\title{
A SIMPLES APREENSÃO DO SER: HEIDEGGER E DUNS SCOTUS
}

\author{
The Simple Seizure of Being: Heidegger and Duns Scotus \\ La Simples Captación del Ser: Heidegger y Duns Scotus
}

\begin{abstract}
Resumo: este artigo pretende tratar da visão simples do ser como fonte e horizonte da doutrina das categorias, que Heidegger tinha em vista, ao tratar, em sua tese de habilitação, da doutrina das significações na Gramática Especulativa, então atribuída a Duns Scotus. A doutrina das categorias e sua problemática é o foco em que se acende a questão do ser no caminho do pensamento de Heidegger, questão que, sempre, de alguma maneira, vem junto com a questão da essência da linguagem. A descoberta fenomenológica da intuição categorial oferece um aporte importante para encaminhamento do problema das categorias e, assim, para a colocação da questão do ser. A doutrina das categorias, bem como a doutrina medieval dos transcendentais, tem como pressuposto fundamental a doação prévia da ordem universal do ser (o todo do pensável). A doação do ser é primordial. O ente (no seu ser) é o primeiro objeto do intelecto. A simples apreensão do ser, sua concepção, bem como a sua compreensão é o fundamento a partir do qual se pode colocar a questão do seu sentido.
\end{abstract}

Palavras-chave: ser, categorias, intuição, linguagem.

\begin{abstract}
This article intends to deal with the simple vision of being as the source and horizon of the doctrine of the categories, which Heidegger had in mind, when treating in his habilitation thesis, the doctrine of significations in Speculative Grammar, then attributed to Duns Scotus. The doctrine of categories and their problematics is the focus in which the question of being in the path of Heidegger's thinking is raised, an issue which always comes together in some way with the question of the essence of language. The phenomenological discovery of categorial intuition offers an important contribution to the problem of categories, and thus to the questioning of being. The doctrine of categories, as well as the medieval doctrine of the transcendental, has as its fundamental presupposition the prior giving of the universal order of being (the whole of the thinkable). The gift of being is primordial. The being is the first object of the intellect. The simple apprehension of the being, its conception, as well as its comprehension is the foundation from which one can put the question of its meaning.
\end{abstract}

Keywords: being, categories, intuition, language.

Resumen: Este artículo pretende tratar de la visión simple del ser como fuente y horizonte de la doctrina de las categorías, que Heidegger tenía en vista, al tratar, en su tesis de habilitación, de la doctrina de las significaciones en la Gramática Especulativa, entonces atribuida a Duns Escoto. La doctrina de las categorías y su problemática es el punto central que enciende el debate del ser en la línea del pensamiento de Heidegger, cuestión que, siempre, de alguna manera, viene junto con el debate de la esencia del lenguaje. El descubrimiento fenomenológico de la intuición categorial ofrece un aporte importante para encaminar el problema de las categorías y, así, para el planteamiento de la cuestión del ser. La doctrina de las categorías, así como la doctrina medieval de los trascendentales, tiene como presupuesto fundamental la donación previa del orden universal del ser (el todo del pensable). La donación del ser es primordial. El ente (en su ser) es el primer objeto del intelecto. La simple aprehensión del ser, su concepción, así como su comprensión es el fundamento a partir del cual se puede plantear la cuestión de su sentido.

Palabras Clave: ser, categorias, intuición, lenguaje.

O problema das categorias e a questão do ser em conexão com a questão da linguagem. 0 aporte da descoberta da intuição categorial para o questionamento desta dúplice questão (do ser e da linguagem).

O problema das categorias está sob o toque da questão do ser, que, desde o início do seu caminho de pensamento, impele Heidegger ao filosofar, como uma necessidade premente (Heidegger, 1978, p. 55). A doutrina das categorias serve, na verdade, como um foco (ponto de acendimento do fogo) para esta questão. Recordemos, com efeito, que uma das múl- tiplas significações do ente segundo Aristóteles, estudadas por Brentano, cuja tese fora decisiva na iniciação do jovem Heidegger na filosofia, é aquela que concerne às figuras das categorias (Brentano, 1996, $\mathrm{p}$. 13-15). O ser vem à fala nas muitas significações do ente. Em que medida e em que sentido nesta multiplicidade se vela uma simplicidade? Eis o início da questão de "Ser e Tempo": a busca de um sentido uno e simples (Einfach) no múltiplo e multifário (Mannigfach) das suas significações (Heidegger, 1978, p. 56).

Junto com a questão do ser, porém, se apresenta a questão da linguagem. O ente enquanto ente, na metafísica, é indagado tendo como fio condutor o lógos, isto é, a linguagem. O ente é, pois, apreendido como 
on legómenon, isto é, como o ente que vem à fala, que é dito (de muitos modos). $\mathrm{O}$ ente vem ao encontro e se deixa encontrar de muitos modos e assim se deixa dizer. O primeiro grupo de modos é, pois, o do ente segundo as figuras das categorias: tò on ... katà tà schémata ton kathegoriôn ${ }^{1}$. Estas são modos de ser que são determinados no discurso, mais propriamente na proposição. O lógos, o discurso, em especial, a proposição, a asserção, é a indicação do ente nestes modos de ser. É o que torna o ente acessível em seu ser. O lógos tem uma orientação ontológica: torna acessível, deixa e faz ver, os modos de ser do ente. E vice-versa: o ser se deixa colher e apreender através do lógos doando-se no modo de uma intuição categorial - que é, justamente, uma apreensão simples do categorial (Husserl, 1993, p. $115-164)^{2}$.

No tocante às categorias, Husserl foi além de Kant: para aquele a categoria é mais do que uma forma do entendimento, que informa os dados hiléticos (da sensibilidade). A categoria se manifesta como algo dado (als Gegebenes) (Heidegger, 1986, p. 375). Deste modo, não só o sensível, mas também o categorial aparece como "efetivo" e como "dado ele próprio". Ele não somente é pensado, ele é intuído, percebido, apresentando o caráter de autodatidade. A intuição categorial é análoga à intuição sensível. O categorial e ontológico torna-se fenômeno, assim como o sensível e ôntico. Ou, pode-se até mesmo dizer que o categorial e ontológico é mais fenômeno do que o sensível e ôntico (Heidegger, 1986, p. 376-377). Isso não implica, porém, que os correlatos objetivos das formas categoriais sejam momentos "reais", isto é, da coisa ${ }^{3}$. Seus correlatos objetivos, com efeito, não se deixam encontrar na esfera dos objetos reais. Mas, por outro lado, estas datidades não podem ser consideradas meros produtos da reflexão subjetiva.

1 Brentano, ao começar a exposição sobre esta significação do ente segundo Aristóteles, diz ser ela a mais importante e, ao mesmo tempo, a mais difícil. A ela dedica o quinto capítulo de sua tese, o mais extenso de todos.

2 A intuição categorial emerge no sexto capítulo da sexta das Investigações Lógicas (logische Untersuchungen) de Husserl, a qual visa elucidar fenomenologicamente o conhecimento a partir da análise de seus elementos fundamentais. A intuição (Anschauung) é um destes elementos fundantes do conhecimento. Ela é uma apreensão direta do fenômeno, isto é, do que está doado, no como de sua autodatidade. Ela é fonte de evidência (Evidenz). Por sua vez, a evidência é o conhecimento no sentido pregnante do termo. É na evidência que se realiza a verdade, enquanto concordância (Übereinstimmung) entre intentio e intentum. Partindo de enunciados de percepção, Husserl percebe que, mesmo nos mais simples, se dá uma excedência de significação, que não pode ser preenchida com intuições sensíveis. Os enunciados contêm não somente "matéria" expressa por termos nominais, eles trazem consigo também formas categoriais. Com outras palavras: nos enunciados há palavras cujas significações não são materiais, mas formais, tais como $o$, um, alguns, muitos, poucos, dois, é, não, qual, e, ou e assim por diante. São partes de enunciado cujas significações não encontram correspondência na intuição sensível. Estes elementos não se deixam atestar no percebido, caso percepção signifique, aqui, somente a apreensão de uma intuição sensível. Husserl realiza então uma ampliação de sentido de percepção e de intuição, indo além do sensível, na esfera do categorial. As significações categorialmente informadas se relacionam com objetos categoriais. Assim convertem-se em "objetos", já na linguagem usual, conjuntos, pluralidades indeterminadas, totalidades, números, formas disjuntivas, predicados (o ser-justo), estados de coisas, enquanto os atos, por meio dos quais eles aparecem como dados, convertem-se em "percepções".

3 São formas categoriais, por exemplo, o ser, o é, o um e o o, o e e o ou, o se e o então, o todos e o nenhum, o algo e o nada, as formas da quantidade e as determinações numéricas etc.
Ao sentido interno, à reflexão, se manifestam atos da consciência, tais como julgar, desejar, representar, perceber, recordar, etc. Enquanto são dados ao sentido interno, são sensíveis e são também reais e objetivos - com efeito não há somente o objetivo-objetivo (transcendente à consciência), mas também o objetivo-subjetivo (imanente à consciência). Os correlatos das formas categoriais não são coisas objetivas (objetivo-objetivo), mas também não são atos ou vivências subjetivas (objetivo-subjetivo) ${ }^{4}$. Husserl (2000, p. 132-133) diz:

A origem dos conceitos de estado de coisas e de ser (no sentido da cópula) não está verdadeiramente na reflexão sobre juízos, ou melhor, sobre preenchimento de juízos, mas nos próprios preenchimentos de juízos; não é nesses atos enquanto objetos, mas nos objetos desses atos que encontramos o fundamento de abstração que serve para a realização dos ditos conceitos.

Os correlatos objetivos das formas categoriais não são nem físicos nem psíquicos. E, no entanto, são algo dado, possuem o caráter de datidade. Isso vale também para a forma categorial do ser, quer na função atributiva, quer na função predicativa. Há ser, isto é, dá-se ser. Para o encaminhamento do jovem Heidegger para a questão do ser, a descoberta de Husserl da intuição categorial foi decisiva. Ela libertou o ser de sua fixação no juízo. É a partir daqui que Heidegger trabalha na questão do sentido do ser. Para que se possa perguntar pelo sentido do ser é preciso haver uma concepção do ser, vale dizer, uma intuição do ser. Isto quer dizer: o ser precisa ser dado, para que junto a ele se pergunte originariamente a respeito de seu sentido. A descoberta da intuição categorial presentifica o ser, que se torna vigente-presente de modo fenomenal na categoria. Isso quer dizer que ser não é uma pura abstração, algo apenas pensado, e derivado do entendimento, ou mero produto da reflexão do sujeito. Ser se doa como uma originária datidade. Melhor: se doa a si mesmo numa originária autodoação. Isso que se oferece na intuição, oferece o terreno para elaborar as estruturas das categorias. Não sendo meras funções do pensamento, nem propriamente criações do sujeito, as categorias adquirem um caráter autenticamente objetual ou objetivo. Tal objetividade e objetualidade, certamente, se encontra numa relação intencional com a subjetividade, mas como o intuído de um intuir, de modo análogo à intuição sensível. Trata-se de uma intuição doadora; trata-se de um ser-dado, de uma datidade. Com a investigação fenomenológica das estruturas que nessa correlação funcional se abrem se resgata o tipo de investigação ao qual mirava a antiga ontologia. Fenomenologia e ontologia não são duas coisas

\footnotetext{
4 Husserl nega que a origem do conceito de ser está na reflexão, isto é, na percepção interna. Quando ponho em ato o juízo e digo o enunciado predicativo "o ouro é amarelo", o “é” não se encontra no ouro, ao modo do amarelo; o "é” também não se encontra no juízo, isto é, no ato de julgar, que posso perceber internamente. $\mathrm{O}$ enunciado dá expressão a um estado de coisas. A percepção do estado de coisas enquanto tal capta algo que sobrepuja todo objeto sensível, seja externo, seja interno. O "é” não pode ser percebido como objeto nem para a percepção sensível externa nem para a percepção sensível interna.
} 
diversas. Fenomenologia não é outra coisa do que a realização da ontologia em seu sentido e escopo. A ontologia, enquanto ciência do ser, não é outra coisa do que fenomenologia (Heidegger, 1994, p. 97-98).

Esta doação, essa datidade do ser, no entanto, se torna acessível, na linguagem e pela linguagem. A tese de habilitação de Heidegger, de certo modo, mantém este horizonte, já presente na tradição filosófica desde os gregos, à medida que, para tratar a doutrina das categorias (Kategorienlehre), resolve tratar da doutrina da significação (Bedeutungslehre), a partir da "Grammatica Speculativa", até então atribuída a Duns Scotus. Aqui a "Grammatica Speculativa" é exposta como uma doutrina da significação (Heidegger, 1978, p. 210). Por sua vez, o estudo da morfologia das significações (Formenlehre der Bedeutungen), para usar uma expressão de Husserl, tem como sentido abrir caminho para a investigação das diferentes formações categoriais (kategorialen Formungen) (Heidegger, 1978, p. 203).

O que se visa, assim, é a explicitação dos modos fundamentais do ser do ente, isto é, das determinações fundamentais que afetam o ente em seu todo, através do estudo das formas fundamentais de enunciados sobre o ente enquanto ente. Com isso, também, vêm à fala os diferentes domínios da realidade, interrogando-se, a cada vez, em relação a cada um destes domínios, a respeito de sua natureza e modo específico de apresentação (Artung), de sua estrutura (Struktur) e de sua constituição (Verfassung) (Heidegger, 1978, p. 211). A investigação do categorial, no pensamento do medievo, ultrapassa de muito o estudo das categorias postas em relevo por Aristóteles. Aqui tem-se claro "que as categorias aristotélicas aparecem apenas como uma determinada classe de um determinado domínio e não como as categorias pura e simplesmente" (Heidegger, 1978, p. 211). Uma doutrina das categorias deveria, assim, conduzir a uma explicitação dos diferentes domínios da realidade e de seus modos próprios de ser. O escopo da investigação é, portanto, expor o fenômeno do categorial, como uma camada (Schicht) todo própria, e, destarte, dar acesso à estrutura categorial dos diferentes domínios da realidade (Heidegger, 1978, p. 211).

Assim, sob a figura do problema das categorias se vela a questão do ser e da linguagem (Heidegger, 1978 , p. 55). A investigação impostada em termos de história dos problemas tem, portanto, um escopo sistemático, que se deixa anunciar sob o título de "doutrina das categorias". É enquanto investigação impostada em termos de história dos problemas que a filosofia de Duns Scotus é tomada por Heidegger como objeto de indagação. Esta é considerada e estimada em seu valor para o exercício do pensamento como um dos tipos mais completos e ricos do pensar medieval-escolástico. O escopo proposto então era o de trazer este pensar ele mesmo mais para perto e para uma compreensão mais profunda naquilo que concerne ao problema das categorias e da lógica em geral (Heidegger, 1978, p. 412). A primeira parte da dissertação visa, com efeito, a doutrina das categorias. Detém-se na exigência fundamental de uma tal doutrina: "A delimitação dos diferentes domínios dentro do objetual em geral", isto é, do ente no todo (Heidegger,
1978, p. 412). De início trata das determinações mais gerais do objeto em geral, o que leva a investigação a tratar das "transcendentia", ou seja, dos transcendentais do pensamento medieval, mormente do ens, do unum e do verum. O bonum não é contemplado visto que a investigação tem um escopo teorético e não prático. A partir daí se expõem os domínios particulares do ente como um todo, isto é, a realidade lógica, a matemática, a física, a psíquica e a metafísica (Heidegger, 1978, p. 412). Esta exposição, porém, tem caráter exploratório, provisório, fragmentário.

Da consideração do ser do ente (do ente no todo e nos seus domínios particulares) se passa, então, à consideração da linguagem, isto é, da doutrina das categorias se passa à doutrina das significações, contida na Grammatica Speculativa. A tese de habilitação assume a exposição da doutrina das categorias como fundamento e infraestrutura para a compreensão da doutrina da significação. Esta relação entre ambas tem sentido metódico. Não decide sobre a coordenação lógica de ambas as circunscrições. Tal decisão somente seria possível uma vez esclarecidos plenamente ambos os fenômenos (do categorial e da significação) (Heidegger, 1978, p. 212). Em todo o caso, a segunda parte, que trata da esfera objetual das significações, se assenta sobre a primeira parte, que trata do categorial. Nessa segunda parte, são considerados os atos de significação e os atos de conhecimento. Heidegger, em sua interpretação, entrelaça elementos da doutrina da significação presentes em Husserl e em Duns Scotus. A doutrina dos modos de significar, de inteligir e de ser, da Grammatica Speculativa, é por ele lida a partir da análise intencional fenomenológica. Trata-se do esforço fenomenológico de abrir e esclarecer o "mundo das significações" tomado como uma nova e autônoma região do ser (do ente como todo) (Heidegger, 1978, p. 303). É o dar-se desta esfera objetual ou desta região de ser que justifica a necessidade de uma doutrina das significações. Aqui se levanta também a questão concernente ao tratamento filosófico da linguagem: até que ponto e em que medida a filosofia há de se ocupar com a "linguagem" e pode fazê-lo. Depois, como é que as relações da doutrina da significação hão de ser pensadas como concernentes à lógica (Heidegger, 1978, p. 303). Estas questões constituem o horizonte do tratamento da parte geral da "Grammatica Speculativa", que trata dos princípios da doutrina da significação ${ }^{5}$.

Em seguida, expõe-se e interpreta-se a parte que trata da morfologia das significações (Formenlehre der Bedeutungen), que, na "Grammatica Speculativa" se realiza no modo de uma teoria dos "modi significandi" (modos de significar). Aqui são tomados em consideração, na esteira do gramático Donato, as oito partes do discurso (Redeteile): nome, pronome, verbo, advérbio, particípio, conjunção, preposição e interjeição. No último capítulo, por sua vez, Heidegger tenta não somente apontar o que há de potencial no tratamento destes problemas, bem como algumas soluções. A consciência da insuficiência da empreitada se expressa no mote que Heidegger escolheu para esta parte conclusiva, que é uma sentença de Novalis: "Wir suchen überall das Unbedingte und finden immer

\footnotetext{
$5 \quad$ Cf. o primeiro capítulo da segunda parte da tese de habilitação, intitulado "Bedeutung und Bedeutungsfunktion" (Significação e função significativa) (Heidegger, 1978, p. 304-341).
} 
nur Dinge" (Nós buscamos em toda a parte o Incondicionado e só encontramos sempre coisas) (Apud Heidegger, 1978, p. 399).

Importante notar que a investigação de Heidegger não tem um escopo historiográfico. Não obstante se tratar de uma investigação realizada em termos de história dos problemas, o seu escopo é teorético-sistemático. Trata-se, pois, não em primeiro lugar de uma história dos problemas, que visa auferir resultados historiográficos, mas de uma história dos problemas, que visa abrir perspectivas teoréticas-sistemáticas, concernentes à "doutrina das categorias" e à "doutrina da significação". O que é visado, sempre, em última instância, é uma "compreensão teorética" dos problemas tratados (Heidegger, 1978, p. 304). A investigação da tese de habilitação tem um caráter sistemático: visa reunir os elementos dispersos da doutrina das categorias num todo bem articulado.

Não obstante, o modo unitário com que a dissertação articula questões históricas e questões sistemáticas prenunciam a compreensão própria do filosofar fenomenológico. Com efeito, para a fenomenologia não tem sentido a separação, até certo ponto útil do ponto de vista didático, entre os modos de consideração histórico e sistemático (Heidegger, 1987, p. 125). Os temas e problemas da filosofia não pertencem a um âmbito atemporal, desvinculados do horizonte cairológico e das vicissitudes de uma época, de uma geração ou mesmo de inteiras gerações. Há que buscar as suas verdadeiras motivações na história do espírito. Por espírito entende-se, aqui, a dimensão da liberdade onde se jogam os destinos históricos das culturas e dos povos. É a dimensão profunda, subterrânea, fundamental da história. Neste sentido a perspectiva de uma "história dos problemas" requer ser situada no horizonte de uma "história do espírito". Na tese de habilitação, aqui e ali elementos de considerações sobre o pensamento medieval concernentes à "história do espírito" vêm à tona. Mas, para a fenomenologia, pensada desde a questão do ser, ambas as formas de tratar a história da filosofia são insuficientes. Heidegger, porém, ainda teria que caminhar bastante para chegar à forma de consideração própria da história da filosofia, chamada de "histórico-ontológica" (Seinsgeschichtlich).

Da mesma maneira que o caráter histórico da investigação filosófica precisa ser bem entendido, o mesmo acontece com o seu caráter sistemático. A investigação filosófico-fenomenológica precisa ser unitariamente, histórico-sistemática. Por sistema, ainda é necessário esclarecer, entende-se, aqui, a conexão unitária dos problemas, através da qual eles aparecem reunidos numa con-juntura referencial. Interessa, sobremodo, descobrir como é que determinados temas e problemas remetem a outros de modo recíproco, assim como observar como se dá uma mútua remissão das diversas tentativas de resolução assumidas pelas diversas posições dentro da história da filosofia. Sob a configuração dos problemas, porém, que aparecem objetivamente na história da filosofia estão em vigor as questões fundamentais. Os problemas têm certo caráter objetivo. As questões filosóficas, que os motiva, porém, são mais fundamentais e abrangentes e incluem de cheio aqueles que as questionam. Dentre elas, aquela questão mais fundamental e fundante de todas, apaixonadamente investigada por Heidegger: a questão do ser - que está em íntima conexão com a questão da linguagem. É para esta dúplice questão que a investigação da tese de habilitação de Heidegger se direciona, não obstante todo o seu caráter incoativo e seus resultados provisórios e superáveis. Aqui mais do que nunca vale a sentença de Novalis escolhida para mote da sua conclusão, há pouco mencionada: Nós buscamos em toda a parte o Incondicionado (das Unbedingte) e só encontramos sempre coisas (Dinge).

\section{A Ordem Universal do Ser: 0 Todo do Pensável e a Doutrina das Categorias e dos Transcendentais}

O domínio, melhor, o mundo das significações é um daqueles domínios da realidade que uma elaboração da doutrina das categorias tem como tarefa trazer a uma dilucidação e diferenciação. Isso implica também e sobretudo esboçar, perfilar, o todo do pensável (das All des Denkbaren). Cada fenômeno deve poder ser situado num "lugar lógico", isto é, cada fenômeno exige, segundo seu conteúdo, um determinado lugar nesse todo do pensável. O "lugar", em sentido lógico, porém, só pode ser situado a partir de um conjunto, de um todo de relações (Beziehungsgan$z e s)$, que, por sua vez, se funda numa ordenação.

A doutrina dos transcendentais, na Idade Média, é fortemente marcada pelo pensamento da ordenação. No medievo, o todo do ente, da realidade, é "ordo". O ente no todo constitui, pois, a ordem universal. A partir daí é que se delineiam as partes da totalidade do ente, da realidade (ordens regionais) Cada ente pode se localizar em ordens diferentes a depender do ponto de vista em que se o considera. Em questão está, pois, a cada vez, um todo de relações. Impõe-se, aqui, o problema das relações entres as ordens regionais dentro da ordem universal: o ser, no sentido de "ente no todo". Seja como for, todo ente enquanto tal se acha já em uma ordem, a saber, na ordem universal do ser. A palavra grega "lógos" pode evocar esta ordem universal do ser (o ente no todo). Lógos (de légein: colher, recolher) quer dizer recolhimento, força de reunião, articulação de sentido. Lógos diz, pois, a reunião do todo do ente, a reunião do ente no ser. Cada ente tem seu lugar no ser. Conhecer é um exercício do pensar que realiza a identificação de um objeto particular apreendido (ente particular), determinando-se sua significância essencial, bem como o lugar que este objeto (ente) ocupa na estrutura essencial da totalidade do ser. Sem a abertura prévia da totalidade do ser, em sua universalidade (mundo), não se pode conhecer nada de particular. As categorias (e os transcendentais) são os momentos estruturantes desta estrutura essencial da totalidade do ser. O lógos, isto é, a reunião do ente no ser, se manifesta ao e no pensar. O pensar pertence, com efeito, ao ser, enquanto sua manifestação (Heráclito, Parmênides); assim como o ser pertence ao pensar, enquanto o pensável e o pensado deste pensar (Platão, Aristóteles). O lógos, reunião primigênia do ente no ser, que reina constantemente e por 
toda a parte, requisita o pensar do homem, a ele se doa e solicita nele se manifestar. Alcança esta manifestação no dizer da linguagem. Por isso, de certa maneira, chama-se de lógos também ao pensar que acolhe e recolhe a manifestação do ser e, não menos, chama-se de lógos o dizer (mostrar) do ser na linguagem (enquanto fala, discurso, enunciado, etc.). Pode-se chamar de lógos, também, esta conexão, esta unidade, de ser-pensar-dizer. No homem, o lógos é a sua participação vital nessa ordem do ser, que é também a ordem do pensar (o todo do pensável) e do dizer (Heidegger, 1987, p. 208).

Tudo isso delineia a pressuposição para uma doutrina das categorias (em sentido amplo, que implica também a doutrina dos transcendentais). Todo o ente enquanto tal já se acha na ordem universal do ser (que abre, ao mesmo tempo, a ordem do pensável e do dizível). Esta ordem é a condição de possibilidade do delinear de um todo de relações e, por conseguinte, do exercício da ordenação (ordem é um todo-uno relacional). Esta é a condição ontológica necessária para que tal ente possa entrar ainda em ordens determinadas, regionais, particulares, as quais se perfilam, cada vez, em estruturações com constituições próprias. Do ponto de vista ontológico, toda ordem particular se baseia e se funda, quanto à sua possibilidade, na ordem universalíssima e primigênia do ser. $\mathrm{O}$ traço fundamental de relação, que caracteriza a toda a ordem, aparece com especial clareza na doutrina dos transcendentais do medievo, que é marcado fortemente pelo pensamento da ordem.

Tanto a ordem universal do ser como os diversos domínios da realidade não podem ser provados, isto é, demonstrados por via dedutiva (beweisen) (Heidegger, 1978, p. 213). Só podem ser mostrados, indicados em sua facticidade (aufweisen, aufzeigen). Isso que se deixa mostrar assim está ele mesmo diante de nós como o i-mediato, isto é, como o que se dá sem mediação, o que não precisa de graduações, de aproximações progressivas. O ser se dá como um todo simples. É o originário: o que salta sempre de novo e novo diante do olhar e, assim, o detém. E, detendo-o, dirige seu apelo, solicita ser colhido, recolhido, acolhido, como ele mesmo, a partir dele mesmo, nele mesmo. Ser é o fenômeno originário que se dá imediata e simplesmente e que, dando-se assim, solicita um ver simples (schlichtes Sehen), segundo se diz na fenomenologia contemporânea, requer somente uma simples apreensão (simplex aprehensio), conforme se dizia na fenomenologia medieval. Entre a doação do fenômeno originário, imediato, simples, universal, do ser, e a simples apreensão não há nada, nenhuma mediação, nenhuma graduação, nenhuma distância a ser percorrida. Ao pensar cabe apenas a recepção - a doação da recepção, a entrega obediente ao fenômeno... Apenas? Como se isso, por ser simples, fosse fácil... O deixar-ser da recepção do pensar é, sim, simples. Mas, por isso mesmo, exigente, difícil ${ }^{6}$.

6 Nós nos relacionamos com a evidência do ser como o morcego com a luz, segundo uma famosa passagem de Aristóteles (Cf. Aristóteles, Metafísica $\alpha$ (II) 993b 9-11) que diz: assim pois como os olhos do morcego se comportam em face da luz do dia, assim também o intelecto que está em nossa alma se comporta em face daquelas coisas que por natureza são as mais manifestas. Fazendo
É preciso aprender a ver, apenas ver, o que se mostra, o que se oferece nessa imediatez e simplicidade. Aqui todo o raciocínio, toda a dedução, todo o cálculo, toda definição, toda análise e toda síntese, toda somatória, toda determinação de relações e funções, chegam tarde. Aprender a ver - eis o sentido do exercício fenomenológico, que constitui o ofício dos pensadores, quer se trate da fenomenologia do pensamento grego, quer do medieval, quer do moderno e hodierno. O todo simples do ser, as suas propriedades transcendentais, os seus diversos domínios ou regiões, precisam ser vistos, simplesmente. Em relação a eles se dá um manifestari não um demonstrari (Heidegger, 1978, p. 216). Mais do que a ratio (razão) enquanto ratiocinatio (raciocínio), o que está em jogo, aqui, é a simplex aprehensio (simples apreensão) da ratio enquanto olhar da mens (mente), da ratio enquanto intellectus (no sentido de recepção, colhimento, acolhimento, recolhimento do que simples e originariamente se dá) ${ }^{7}$. O que está em jogo, aqui, é, pois, o

eco a Aristóteles, no século XIII, e falando da luz do ser, Boaventura de Bagnoregio disse: "Mira igitur est caecitas intellectus, qui non considerat illud quod prius videt et sine quo nihil potest cognoscere” (Admirável, pois, é a cegueira do intelecto, que não considera aquilo que por primeiro vê e sem o que não pode conhecer) (Boaventura, 1999, p. 334). Assim, quando se trata da evidência do ser, vemos, mas não vemos que vemos. Admirável é esta cegueira, pois não vê que vê o que há de mais evidente. Conhecemos, aqui, o ser, mas como que às apalpadelas.

7 "Razão (ratio) é a mirada da mente (mentis aspectus), e raciocínio (ratiocinatio) é a indagação da razão (rationis inquisitio), ou seja, o movimento (motio) da mirada da mente sobre aquilo que deve examinar. Essa indagação, ou raciocínio, é necessária para a procura (opus est ad quaerendum), para ver (ad videndum). Quando esse olhar da mente, chamado razão, concentrado em (conjectus) alguma coisa, a vê (videt), denomina-se ciência (scientia nominatur). Quando não consegue ver, por mais esforço que empregue, chamamos ignorância” (Agostinho, 1997, p. 126 - tradução modificada). Mens, mentis: não é fácil determinar o significado preciso de mens. Mesmo porque, em sua significação acontece uma natural oscilacão. Também é assim no uso que os medievais fazem desta palavra fundamental do pensamento. Dependendo do contexto o sentido sofre uma ligeira modificação. Grosso modo, a palavra latina mens pode significar mente, espírito, inteligência; mas também intenção, projeto; ânimo, coragem; disposição de espírito; memória; razão. A palavra latina mens provém de um radical: mn-. Em Sânscrito temos a palavra manyatê, pensar, intencionar. Em grego temos a palavra "ménos". Esta quer dizer: força, vigor, potência, violência; força vital, princípio de vida, vida; mas significa também força de ânimo, coragem, paixão, furor; e, ainda, vontade, intenção, propósito. Ménos nomeava o ser, entendido originariamente como o irromper em todo o seu vigor, por exemplo, o irromper de uma tempestade. Também se podia falar de ménos do sol: o seu irromper, surgir, aparecer e brilhar cheio de vigor. No grego moderno ménos que dizer fogo, ardor. No grego antigo há também a palavra mémona, que é um perfeito arcaico, cujo sentido é: pensar fortemente em, te a intenção de, desejar, ser pleno de ardor, de coragem para... Assim, o vigor intenso e ardente que irrompe como vitalidade do homem, que vige como paixão e como potência de pensar, de recordar, de intencionar, de querer, de amar... é a mente. O perfeito mémona corresponde ao latim menini, recordar (cfr. o grego mimnesko, que é, também, recordar; bem como o substantivo mnéia, recordação). Este mesmo radical mn- está no inglês "mind" (mente). Está também no alemão: em Meinung (intenção) e em Minne (amor), palavra cara a Mestre Eckhart, que guarda em sua significação algo de aspirar a, de recordar (Minne Trinken = beber para celebrar o amor), de bem-querer, com solicitude e ternura. Mente quer dizer, assim, intenção, no sentido de intencionalidade (fenomenologia!) intencionalidade não como simples dirigir-se-a-alguma-coisa da consciência (Husserl), mas como o direcionar-se, o orientar-se, do humano em sua existência, como ser-no-mundo (Heidegger), isto é, como ente em relacionamento com o mundo circundante (Umwelt), com o mundo compartilhado da convivência (Mitwelt), com o mundo de si mesmo (Selbstwelt). Mente quer dizer, pois, a intencionalidade enquanto ser-junto às coisas e ser-com o outro. É 
simples noein: o perceber intelectivo, que apreende, à medida que desvela, numa simples apreensão, o ser do ente em sua simplicidade, bem como as suas determinações simples (Heidegger, 2012, p. 64). O noein é um perceber (vernehmen) que se realiza no modo de um receber (annehmen), que colhe, acolhe, recolhe o dar-se do ser mesmo em sua simplicidade e em suas determinações simples. Ele realiza uma intuição, que tem a sua própria evidência, aquela ontológica. E, pois, um relacionamento de ser com o ser, a saber, um relacionamento que acontece no modo do ser-desvelante-do-ser.

Aquele que se mantém desperto e está atento para o olhar da simples apreensão sabe o que já advertia Aristóteles no livro IV da Metafísica (Metafísica 1006 a 6s): é, pois, falta de educação, de formação, não ter nenhuma visão ou conhecimento, daquilo em relação a que é necessário buscar uma demonstração e daquilo em relação a que isso não é necessário. Aquilo que diz respeito à manifestação simples e imediata do ser, bem como das suas determinações originárias e universais, e dos seus princípios pertence àquilo de que não se há de buscar demonstração. Isso se mostra. Requer a simples apreensão, o aceitar e acolher, o perceber imediato. É o domínio do que é próteron te physei: primeiro segundo a phýsis, isto é, segundo o dar-se e abrir-se da realidade como tal e como um todo. É o domínio das datidades originárias - o âmbito do que é simples e imediato. Disso nós temos apreensão, mas nós nos dispensamos de um questionamento essencial, justamente por considerarmos como o domínio do óbvio. O discurso, aqui, pode indicar (zeigen), isto é, tentar ajudar a ver, deixar-ver, no sentido do mostrar (aufweisen, aufzeigen). Mas não pode demonstrar, no sentido de dedutivamente provar (beweisen). Nesse domínio, o que se doa ilumina-se a partir de si, em si. Aqui não está em jogo uma comprovação, uma dedução ou uma conexão causal. Aqui está em jogo a identificação da "coisa mesma", isto é, do fenômeno, do que se manifesta a partir de si e em si. Identificação é, aqui, antes de tudo, o mostrar-se do fenômeno mesmo, em si mesmo, a partir dele mesmo. É, além disso, a experiência do ser idêntico entre o presumido do discurso e o intuído como tal (apreensão vivente, implícita, do ser-idêntico na sua evidência). Identidade significa, aqui, então, coincidência, a saber, de pensar e ser.

\section{O Ente (No Ser) como Primeiro Objeto do Intelecto}

O primeiro capítulo da tese de habilitação de Heidegger começa com a indicacão fundamental: a intencionalidade enquanto $D a$-sein. É preciso entender a palavra não simplesmente em sentido psicológico, mas, muito mais, em seu sentido ontológico. Mens é o que é o mais próprio do homem; é o ser do homem enquanto abertura, isto é, potência de recepção para a doação do ser, do sentido do ser, da verdade do ser de tudo o que é. O ser do homem, aquilo que os medievais chamavam de "mens" (mente) e que Heidegger chama de Da-sein (ser o aí para a proximidade do ser) é o vigor cordial desta abertura para a evidência, para o simples ver, para o simples captar do vir à luz, do fenômeno, entendido como manifestação e brilho do ser. Ser-homem é existir isto é, insistir nesta abertura. Mens é o ápice do ser do homem, de suas possibilidades de ser, de ser para o manifestar do ser, para a sua verdade manifestativa, anterior a toda a verdade predicativa.
"Toda região objetual (Gegenstandsgebiet) é uma região objetual (Gegenstandsgebiet)". Aqui se tem em mira o "objeto como tal", versão da filosofia transcendental moderna para o "ente". O discurso da tese, portanto, se desenvolve em certa ambiguidade: entre a "filosofia transcendental dos antigos", como se expressa Kant, e a filosofia transcendental dos modernos $^{8}$. É, portanto, uma pesquisa que trilha sobre dois binários a sua investigação: o da filosofia transcendental do antigos (leia-se, medievais) e o dos modernos (sobretudo kantiana, ou, mais precisamente, neo-kantiana). Interessa-nos, porém, ressaltar os "momentos de consideração fenomenológica" de ambos os tipos de pensamento, para usar uma expressão de Heidegger na própria tese de habilitação (Heidegger, 1978, p. 202).

O objeto (Gegenstand) é um algo contraposto (ein Etwas gegenüber). Aqui, o conceito de "objeto", em certo sentido, coincide com o conceito de "ente", embora o momento da contraposição (do "gegenüber") tende mais à compreensão do ser moderna, que pensa o ente, o real, entendendo a realidade como objetualidade, isto é, em retrorreferência à subjetividade

8 Kant trata dos transcendentais no $§ 12$ da edição-B da Crítica da Razão Pura. Os transcendentais são introduzidos por ele como "conceitos puros do entendimento" (reine Verstandesbegriffen), embora não possam ser contados entre as categorias. Evoca a sentença escolástica: "quodlibet ens est unum, verum, bonum”. Embora subestime as consequências desse ensinamento, no entanto, observa que se trata de um pensamento que se manteve e resistiu longamente na história, apesar de um aparente esvaziamento. Kant recusa a tese de que "unum, verum, bonum" são predicados transcendentais das coisas. Concede, no entanto, que correspondam a exigências e critérios lógicos de todo conhecimento das coisas em geral. Indevidamente, estas exigências lógicas e critérios de conhecimento das coisas em geral, segundo ele, teriam sido falsamente interpretados como predicados (transcendentais) das coisas. Enquanto exigências lógicas e critérios transcendentais da possibilidade do conhecimento das coisas em geral, os transcendentais (unum, verum, bonum) correspondem, na verdade, a três categorias da quantidade, a saber, unidade, pluralidade e totalidade. Em todo conhecimento de um objeto (Objekt) estaria em jogo, com efeito, a unidade do conceito, a verdade das consequências e a perfeição da concordância de fundamento e consequências. Exige-se deste conhecimento, pois, a unidade qualitativa do conceito (unidade da reunião do múltiplo do conhecimento, análogo à unidade do tema, por exemplo, em uma peça teatral, em uma fala ou discurso, em uma fábula) e também a verdade em relação às consequências, o que corresponde à pluralidade qualitativa das notas características: quanto mais consequências verdadeiras se deixam haurir de um dado conceito, tanto mais indícios se têm de uma realidade objetiva (einer objektiven Realität). Tem-se ainda em mira a perfeição qualitativa da recondução dessas muitas consequências à unidade do conceito, pondo-se de acordo completamente com este e a nenhum outro, o que corresponde à categoria da totalidade. Com outras palavras: quanto mais exclusiva for a conexão de um conceito e suas consequências verdadeiras, tanto mais esta é perfeita. Como se pode notar a correspondência entre os transcendentais e as categorias da quantidade se dá em termos de qualidade. Trata-se de unidade, pluralidade e totalidade qualitativas. O que está em conexão, aqui, é a conexão em uma consciência de elementos cognoscitivos heterogêneos através da qualidade de um conhecimento assumido como princípio (Kant, 1968, p. 97-99). Não obstante a crítica de Kant à doutrina dos transcendentais elaborada na filosofia transcendental do antigos, a sua concessão, isto é, o seu reconhecimento de que os transcendentais não são predicados das coisas, mas condições transcendentais, isto é, exigências e critérios do conhecimento das coisas em geral, permite perceber uma certa continuidade entre ambas as filosofias transcendentais. Convém recordar, aqui, a posição de pesquisadores como Gilson e Honnefelder que, por diversos motivos e tendências, afirmaram uma continuidade entre a filosofia transcendental medieval e a filosofia transcendental kantiana (Goris, 2015, p. 488; 492). 
(representatio; ego cogito). Em todo o caso, o conceito tem a mesma universalidade: "toda e cada coisa é um objeto" (Alles und jedes ist ein Gegenstand) (Heidegger, 1978 , p. 214). É na direção desta universalidade que se encaminha a investigação, isto é, na direção daquilo que há pouco se evocava como "ordem universal do ser". Toda região ôntica (objetual) é uma parte, isto é, um domínio da realidade (Wirklichkeitsbereich); é, assim, uma região ôntica, isto é, uma região do ente e, respectivamente, uma região do ser. Aqui, segundo o horizonte da compreensão moderna, o ser é compreendido como realidade, no sentido de realidade efetiva (Wirklichkeit).

Duns Scotus entende o "ens" (ente) como "primum objectum" (objeto primeiro) do intelecto ${ }^{9}$. O plano de fundo da discussão medieval da questão concernente ao primeiro objeto do intelecto não pode ser exposto nos limites deste texto ${ }^{10}$. Scotus, primeiramente, põe a tese de que o "ens" (ente) é o primeiro objeto do intelecto. O sentido medieval de objectum é aqui suposto. Para compreender este sentido é preciso ter em consideração que "objectum", objeto, neste sentido, indica o que está lançado (-jectum) diante da mens (mente), o que vem de encontro $(o b-)$ a ela, em face do perceber, do imaginar, do julgar, do desejar, enfim, em face de toda a mirada da mente (Heidegger, 1996, p. 72-73). Já o subiectum, o sujeito, é o presente, que prejaz, subjaz, a partir de si, e não o que se encontra como tal num representar, como, por exemplo, as coisas. Os significados, pois, de objeto e sujeito, no pensamento medieval, é exatamente o oposto dos significados que usualmente lhes conferimos hoje. O pivô da mudança de significação do obiectum do medievo para o moderno está na mudança de significação do subiectum: que deixou de ser a substância para ser o ego cogito como fundamento, centro de referência, de diferença e de conferência de todo relacionamento com o mundo. Assim o obiectum passou a ser pensado a partir do projeto do subiectum, de seu pôr, representar e constituir.

Em Kant, o Gegenstand, o objeto enquanto ante-posto, é o que está contra-posto, posto em face da consciência (nova configuração da mens), o que se dá a ela, sendo produzido nela e constituído por ela como unidade. O entendimento (Verstand), com base na suprema unidade da apercepção transcendental, e por meio das categorias, associa o múltiplo e variado da intuição em algo unitário: o objeto (Gegenstand $)^{11}$. Kant fala de Objekt e de Gegenstand. O Objekt,

\footnotetext{
9 Duns Scotus coloca a questão sobre o objeto primeiro do intelecto (primum obiectum intellectus), que é uma questão filosófica, dentro de um contexto de uma investigação de teologia fundamental, a saber, no contexto da pergunta pela cognoscibilidade de Deus (de cognoscibilitate Dei). O desenvolvimento desta pergunta pela cognoscibilidade de Deus se dá na Ordinatio, livro I, distinção 3, primeira parte, questão 1 (Ed. Vat. III) (Scot, 1988, p. 83-201). 10 A questão filosófica sobre o primeiro objeto do intelecto é discutida por Scotus dialeticamente, opondo a posição de Avicena, segundo a qual o ente é o primeiro objeto do intelecto, e, do outro lado, a doutrina de Aristóteles, segundo a qual a quididade do ente sensível é o ponto de partida de todo o conhecimento intelectivo. A discussão, porém, torna-se mais complexa em seu caráter dialético, pois Scotus trabalha não somente com a oposição filosófica entre Avicena e Aristóteles, mas também com a oposição filosófico-teológica entre Tomás, que representa o aristotelismo subsumido na teologia, e Henrique de Gand, que é o principal representante do agostinismo no fim do século XIII.

11 Importa, aqui, recordar o § 15 da Crítica da Razão Pura. Em
}

objeto-temático, é, o Gegenstand, objeto-contraposto da experiência científico-natural. Objekt é o Gegenstand cientificamente objetivado, isto é, tematizado científico-naturalmente. Não o que é simplesmente intencionado e representado, mas o que é enfocado, destacado e tematizado segundo o projeto do conhecimento científico-natural. Todo Objekt (objeto-temático-científico-natural) é um Gegenstand (objeto-contraposto-intencionado), mas nem todo Gegenstand (objeto-contraposto-intencionado) é Objekt (objeto-temático-científico-natural). Assim, por exemplo, o que pertence ao domínio da liberdade, o imperativo categórico, o ter que ser ético, o dever moral, é Gegenstand (objeto-contraposto-intencionado), uma vez que se os representa, que se pensa sobre eles, que os intenciona no agir, mas não é Objekt (objeto-temático-científico-natural) (Heidegger, 1996, p. 73).

Duns Scotus fala do "ens" como "objectum", isto é, como o que está posto em face da mente ${ }^{12}$. Trata-se do "primum objectum". O ente se dá numa intuição primordial. Deixa-se captar num conhecimento imediato, primevo, originário. Faz-se conhecer intuitivamente a partir de si com sua pura presença, antes de qualquer abstração (Scotus, 1954, p. 88-89) ${ }^{13}$. O nosso intelecto, em conhecendo este ente - por exemplo, esta pedra, este branco -, elevando-se e abstraindo, pode conhecer o conceito de ente (intentio entis), ali se detendo ${ }^{14}$. O conceito de ente se obtém por abstração. Mas o conhecimento do ente mesmo é intuitivo. Não há ontologia sem fenomenologia, isto é, um discurso sobre o ente (em seu ser) sem a intuição do ente (respectivamente, do seu ser), o colhimento de sua

todo conhecimento do objeto está em jogo uma conjunção (conjunctio). Pode-se falar de uma conjunção do múltiplo intuitivo (quando o múltiplo das representações é dado numa intuição sensível) onde o sujeito é passivo (afetado), e de uma conjunção do múltiplo conceitual, operada pelo intelecto como uma síntese, produzida, portanto, pelo sujeito, como ato de sua espontaneidade. Toda análise e decomposição pressupõe, já, essa síntese ou conjunção. $\mathrm{O}$ intelecto não pode decompor e separar a não ser o que ele compôs e conjugou. $\mathrm{O}$ conceito de conjunção requer a unidade do múltiplo. Conjunção é a representação da unidade sintética do múltiplo. A representação desta unidade não pode nascer da conjunção. É a unidade que torna possível a conjunção e não vice-versa. Esta unidade a priori não se identifica com a categoria de unidade (concernente à quantidade). Todas as categorias se fundam nas funções lógicas do juízo. Nestas, porém, a conjunção, e, por conseguinte, a unidade dos conceitos dados já está pensada. Categoria pressupõe conjunção. A unidade há de ser, portanto, mais elevada: uma unidade qualitativa, conforme já vimos ao se recordar o $\$ 12$. O fundamento da unidade do conceito é o mesmo fundamento da unidade dos diversos conceitos no juízo. Trata-se, da unidade sintética originária da apercepção, enunciada por Kant nestes termos (do § 16): "o eu penso deve poder acompanhar todas as minhas representações...”. Assim, todo o múltiplo da intuição tem uma relação necessária com o "eu penso", no sujeito mesmo em que este múltiplo tem lugar. (Kant, 1968, p. 107-110).

12 "Ens" seria, de modo análogo, na filosofia transcendental moderna, o "Gegenstand überhaupt" (objeto em geral, como tal, pura e simplesmente).

13 "Cognitio abstractive necessario praessuponit aliquando haberi realem praesentiam illius a quo ipsa derelinquitur" (O conhecimento abstrativo necessariamente pressupõe mais cedo ou mais tarde ter a real presença daquilo a partir do qual ela é abandonada): Ord., I, d. 3, p. 1 q. 3 , n. 143

14 "Intellectus noster igitur in concipiendo hoc ens, ut album aut lapidem, ascendendo et abstrahendo potest cognoscere intentionem entis, ibi sistendo" (o nosso intelecto, portanto, em concebendo este ente, tal como branco ou pedra, ascendendo e abstraindo, pode conhecer o conceito de ente, ali se detendo): Lectura, I, d. 3, p. 1, q 1-2, n. 56. 
manifestação, de seu vir à luz (Iammarrone, 2003). O ente não pode ser explicado a partir de outra coisa que nos seja mais conhecida ou familiar: "ens per nihil notius explicatur" (o ente não se explica por nada de mais conhecido) (Scotus, 1950, p. 207) ${ }^{15}$. O ente (no ser) é um dado de evidência imediata.

$\mathrm{O}$ que quer que o nosso intelecto conhece, conhece sob a forma de ente (objeto formal), isto é, em termos de ser. É sob a ótica do ente (na perspectiva do ser) que tudo o que conhecemos vem a ser conhecido. "Ens" não diz, pois, um quê, mas sim um como: é como ente (na perspectiva do ser) que tudo com que nos relacionamos, quer seja o que somos, quer seja o que não somos, tudo de que falamos, se deixa apreender. Assim como cada objeto da visão, seja ele branco, preto ou multicolor, é colorido, assim todo objeto como tal, seja qual for o conteúdo que ele apresenta, é ens (Heidegger, 1978, p. 214). É a partir deste aspecto que tudo o mais é conhecido e compreendido: "Illud est primum obiectum intellectus nostri cuius ratione alia intelliguntur" (Aquele é o primeiro objeto do nosso intelecto, por cujo sentido todas as outras coisas são compreendidas) (Scotus, 1998, p. $629 ; 128)^{16}$. O ente (no ser) abre o sentido que dá inteligibilidade a tudo quanto o intelecto intelige.

O ens é o primum obiectum adaequatum (primeiro objeto adequado) do intelecto. Objeto "adequado" significa mais do que objeto "conveniente"; significa objeto "comensurável". O intelecto se mede com o ente (ser). O ente (ser) é o que é medido pelo intelecto. Mas, por outro lado, também o intelecto se deixa medir pelo ente (em seu ser) ${ }^{17}$. $\mathrm{O}$ ente (respectivamente, o ser) é a medida do intelecto e o intelecto é a medida do ente (do ser). O alcance, a envergadura, do intelecto vai até onde vai o ente; e vice-versa, o alcance, a envergadura, do ente vai até onde vai o intelecto. E neste recíproco medir-se um com o outro, ambos se igualam. É este "igualar-se" que a palavra "adequado" tem em mente. O intelecto alcança a totalidade do ser: o todo de tudo aquilo que é, seja qual for o modo de ser. Intelecto e ente, pensar e ser, estão voltados um para o outro, numa referência originária, numa pertença mútua, de modo que o pensar só é pensar no ser, desde o ser, voltado para o ser, e o ser precisa dar-se ao pensar, nele se manifestar, para vir a ser conhecido como tal. Trata-se de uma identidade na diferença, de uma igualdade na diversidade. Esta identidade diferencial, e esta igualdade entre diversos, entre pensar e ser, intelecto e ente é dimensão de todas as dimensões ${ }^{18}$.

Em relação ao primado do ente na ordem da adequação Scotus diz que o primeiro tem o senti-

15 Ord., I, d. 2, p. 1, q. 1-2, n. 132.

16 De anima, q. 21, n. 1; III, p. 612; Cf. Q. Metaph., IV, q. 1, n. 5; VII, 148.

17 Neste sentido, realismo e idealismo, objetivismo e subjetivismo são posições sempre unilaterais e insuficientes.

18 Quando o intelecto é tomado unilateralmente como a medida do ente, do real, temos o idealismo. Quando o ente, o real, é tomado unilateralmente como a medida do intelecto, temos o realismo. Idealismo e realismo são, assim, unilateralidades. E, como unilateralidades, são apenas a meia-verdade. Cada perspectiva, aparentemente, explica tudo. Só aparentemente, pois um exclui a perspectiva do outro. A tese de uma igualação entre intelecto e ente permite integrar as duas perspectivas, numa concepção mais originária, que apreende a identidade na diferença, a igualdade na diversidade, entre pensar e ser, entre intelecto e ente. do de "praecisio", "precisão" (cf. Ordinatio I, dist. 3, n. 70). Precisão é o caráter do que é preciso. Preciso é aquilo que prescinde de todas as determinações ulteriores ${ }^{19}$. Objeto primeiro adequado do intelecto é aquilo que o intelecto tem em vista exclusivamente, prescindindo de todas as determinações ulteriores, ou seja, aquilo que prescinde de toda diferenciação, mas que é condição de possibilidade de toda decisão distintiva, e de toda concisão definidora no discurso. Perguntar pelo objeto primeiro adequado do intelecto significa indagar: o que é que nosso intelecto por natureza e por destinação está ordenado a conhecer ou inteligir e à luz do qual tudo o mais se torna cognoscível ou inteligível? "Isto é o primeiro objeto da potência cognitiva: aquilo a partir do qual e sob cujo sentido se compreendem todas as outras coisas" ((Scotus, 1998, p. 629; 127) $)^{20}$. Aquilo que, compreendido, abre a compreensão de tudo o mais é o ente.

O ente é o primeiro objeto adequado, preciso, do intelecto, no sentido de que ele é o "maxime scibile" 21 . Segundo Heidegger, "maxime scibilia" é o que é sabido originariamente. Não se trata tanto de uma anterioridade genético-cronológica, mas de uma prioridade em sentido lógico. O conhecimento do "ente enquanto ente" tem prioridade logico-teorética sobre o conhecimento do que quer que seja, pois, é o conhecimento do ser, isto é, da entidade do ente, da realidade do real, da objetividade do objeto enquanto tal. Certamente, o ente não tem o primado na ordem genético-cronológica do conhecimento humano. Na ordem genética, empírica, do conhecimento, o que é por primeiro percebido sensitivamente é o ente singular em ato, e o que é conhecido intelectivamente por primeiro é a sua espécie, e isso, confusamente, isto é, nominalmente, sem definição (Scotus, 1954$, p. $50-51)^{22}$. Duns Scotus recorda, no entanto, o que diz Aristóteles: "que as coisas que são anteriores segundo a geração, são posteriores segundo a substância" 23 . Na ordem da adequação, porém, o que 19 No latim de Duns Scotus "praecisio" ainda guarda a sua origem etimológica. "Praecisus" é particípio passado de "praecido" e, como adjetivo, significa "cortado", "truncado", "escarpado". Só em sentido derivado é que "praecisus" significa "preciso", "conciso". O verbo "praecido" significa "cortar pela frente", "cortar rapidamente", "suprimir", "tirar".

20 Duns Scotus, De Anima, q. 21, n. 1; In Metaphysicam Aristotelis, IV, q. 1, n. 3.

21 Scotus retoma o capítulo 2 do Livro I da Metafísica, que diz que esta é a ciência máxima para o homem. A máxima ciência é aquela que é sobre as coisas maximamente sabíveis (maxime scibilia). As coisas maximamente sabíveis, porém, se dizem em dois modos: ou porque são sabidas antes de todas as coisas, de modo que sem o saber delas não se podem saber de outras coisas; ou porque são coisas cognoscíveis certíssimas (certissima cognoscibilia).

22 Cfr. Ordinatio I, dist. 3, n. 73.

23 Aristóteles, Metafísica, Q, 8, 1050 a 4-5. Para Aristóteles, o ato é, na ordem da essência (da substância, ou da forma), anterior à potência. Por exemplo: o homem adulto é anterior à criança; a árvore desenvolvida é anterior à semente. A realização para a qual algo tende, em sua plena consumação, é o que vem primeiro na ordem da essencialização. O poder se mover para esta realização já está ordenado em vista dela. A matéria está em potência para poder se mover à forma. Quando a matéria está em ato (em plena realização) ela está na sua forma. Em referência à substância, o ato é anterior à potência. Em referência à geração, a potência é anterior ao ato. Tomás de Aquino identifica a anterioridade na ordem substancial com o primado na ordem da perfeição. A geração vai do imperfeito ao perfeito. Mas, na ordem da substância, o perfeito vem primeiro, e o imperfeito está ordenado ao perfeito. Tomás explica que o nome "substância" costuma significar a forma, por meio da qual algo é perfeito (Comentário à Metafísica IX, 8, § 1856). 
por primeiro é concebido, e concebido distintamente, por definição, é o ente. A concepção distinta do ente é a condição de possibilidade de toda concepção distinta, do que quer que seja. Se no tocante ao conhecimento confuso, seguindo a ordem de origem ou geração, o que é concebido por primeiro é o mais particular, a espécie daquele ente que é apreendido sensivelmente, no tocante ao conhecimento distinto, seguindo a ordem da adequação, o que é concebido por primeiro é o que há de mais comum, o ente.

$\mathrm{O}$ ens é o primum objectum distinctum do intelecto. Aquilo que o intelecto pode conceber pode ser confuso ou distinto. "Confuso" significa o mesmo que "indistinto" 24 . Duns Scotus diz que algo é conhecido confusamente quando é concebido como é exprimido por um nome; distintamente, quando é concebido quando é exprimido pela definição (Scotus, 1954, p. 49-50) ${ }^{25}$. Segundo Scotus, "ens" é um conceito distinto, pois ele é absolutamente simples, ou seja, não é composto de nenhuma maneira. É um conceito nítido, determinado, um em si mesmo. Não é confuso, pois não é um todo que compreende partes indistintas. Não é nem um todo essencial, que compreende partes essenciais, nem um todo universal, que compreende partes subjetivas. "Ens", uma vez que é um conceito absolutamente simples, se oferece em sua unidade e simplicidade, "sem dobra", exibindo sua essencialidade, anteriormente a toda "dobra", a toda bifurcação, como, por exemplo, finito e infinito, necessário e contingente, potência e ato, etc.

Aquilo que, compreendido, abre a compreensão de tudo o mais é o ente. O "ens" vem antes de toda determinação. É anterior, por exemplo, à determinação de "substância" (ser-em-si) ou "acidente" (ser-em-outro) (Scotus, 1998, 129) ${ }^{26}$. Heidegger comenta:

24 O confuso é o indistinto nas suas partes. Há, porém, dois tipos de totalidade e, por conseguinte, dois tipos de partes: o todo essencial, que é composto de "partes essenciais"; e o todo universal, que é composto de "partes subjetivas". Um todo essencial tem partes essenciais. A matéria e a forma são partes essenciais de um todo real, isto é, de um composto. O gênero, a espécie e a diferença são partes essenciais de uma definição. Ex.: "homem é animal racional" ("homem” é espécie; "animal” é gênero; "racional” é diferença específica). Um todo universal tem por partes os sujeitos singulares ou específicos dos quais se predica este universal. Por exemplo: "Pedro e Paulo são homens". O conceito "homem” pode ser confuso, quando não se compreende explicitamente as partes deste conceito; seja as partes essenciais, por exemplo, que um homem real é composto de corpo e alma, ou que na definição da espécie "homem" entram "animal" e "racional"; seja as partes subjetivas, quando no universal "homem” eu não explicito que sujeitos (indivíduos) podem receber o predicado "homem". Uma essência ou universal, portanto, pode ser algo de confuso (analisável em várias partes) sem ser conhecido ou compreendido confusamente.

25 Ordinatio I dist. 3, n. 72 . O nome não dá um conhecimento claro e distinto da coisa. A definição, dá. Segundo o Doutor Sutil, o nome é conhecido antes da definição. O nome oferece um conhecimento confuso, isto é, indistinto. A definição oferece, ao contrário, um conhecimento distinto. $\mathrm{O}$ nome comporta confusamente aquilo que a definição comporta distintamente. O conceito da quididade é oferecido confusamente pelo nome e distintamente pela definição. O nome "homem" nomeia uma quididade, dá a conhecer uma quididade de maneira confusa, isto é, indistinta. Já a definição: "homem é animal racional" dá a conhecer uma quididade de maneira distinta.

26 In Metaphysicam Aristotelis, IV, q. 1, n. 40: "Experimentamos em nós mesmos, que podemos conceber o ente, não concebendo este ente em si ou em outro, porque há dúvida, quando concebemos o ente, se é ente em si ou em outro, como se mostra a respeito da luz, se é forma substancial subsistente por si ou se é forma acidental existente em outro; portanto, nós concebemos primeiro alguma coisa de indiferente aos dois, os quais encontramos posteriormente, o objetual (das Gegenständlich) ainda não tem nenhuma determinação categorial mais próxima (1978, p. 214). Pode-se apreender algo em que esteja indeterminado o seu caráter de realidade, e, no entanto, ali se apreende, justamente, um algo (ein Etwas). "Aliquid indifferens concipimus" (Scotus, 1998, 129) ${ }^{27}$. Esse uno, simples, indiferente, é anterior a toda determinação categorial.

\section{A Simples Apreensão do Simplesmente Simples. 0 Ser como o Maximamente Sabível. A Compreensão do Ser.}

Duns Scotus toma em consideração que "ens" (ente, ser) é uma noção "simpliciter simples": "simplesmente simples", quer dizer, puramente, absolutamente, imediatamente simples. "Simples" (simplex) significa "sem algo enlaçado" (sine plexum), "sem dobradura" (sine plicatura), "sem dobrar" (sine plicare): anterior a todo enlace e entrelaçamento, a toda dobra, a toda composição, a toda bifurcação e articulação; positivamente falando: una, inteiriça. A noção de ente/ser não pode ser analisada, ou seja, dissolvida em componentes (Scotus, 1954, p. 49) ${ }^{28}$, por ser absolutamente simples, una. O nome "ens" (ente/ser) traz, pois, uma significação una, indivisa. Ela não pode ser reconduzida a uma noção anterior, que a explicasse.

A noção de ente/ser goza de propriedade manifestadora autoevidente: sua verdade é originária. $\mathrm{O}$ ens (ente/ser) se mostra por si mesmo. E objeto de uma "simplex apprehensio", de uma apreensão simples $^{29}$. E, por isso, não precisa e nem pode ser

e assim o primeiro conceito, que por primeiro é conservado nisto, é o ente".

27 In Metaphysicam Aristotelis, IV, q. 1, n. 40

28 Ordinatio I d. 3, n. 71. Para Duns Scotus, além do conceito de "ens" (ente/ser), também os conceitos das diferenças últimas são absolutamente simples. Diferenças últimas são: diferenças individuais, específicas e genéricas. Há conceitos que são simples, mas que não são simplesmente simples. Conceito simples (não absolutamente simples) é tudo aquilo que pode ser conhecido pelo intelecto por um ato simples, embora possa ser analisado, dissolvido, em vários conceitos, concebíveis separadamente.

29 Tomás de Aquino, em seu comentário sobre o Peri Hermeneias (De Interpretatione) (Proemium, I, 1), fala de três operações do intelecto: a pura apreensão (apprehensio simplex), o juízo e o raciocínio: "una quae dicitur indivisibilium seu simplicium intelligentia vel apprehensio, per quam scilicet intellectus apprehendit essentiam cujusque rei in seipsa; alia operatio intellectus, scilicet componentis et dividentis; aditur et tertia operatio, scilicet ratiocinandi" (uma operação, que se diz inteligência ou apreensão daquelas coisas que são indivisíveis ou simples, pela qual, a saber, o intelecto apreende a essência de qualquer coisa em si mesma; outra operação, é a do intelecto, a saber, do intelecto que compõe e divide; acrescenta-se também a terceira operação, a saber, a do raciocínio). A pura apreensão é a operação do intelecto, pelo qual se tem presente o objeto, sem ainda afirmar nada a respeito dele. Por exemplo: tenho presente o objeto "cavalo”. A segunda operação é a do juízo. No juízo afirmo ou nego um predicado do sujeito. Por exemplo: "O cavalo é um animal”. O raciocínio é a operação pelo qual o intelecto conecta enunciados, passando de um para outro, realizando inferências. Por exemplo: "saindo do meu quarto, apaguei a luz; agora a luz está acesa; logo, alguém entrou, durante a minha ausência, no meu quarto”. A estas três operações intelectivas, correspondem, na lógica, o conceito (que é o pensado da simples apreensão), a proposição ou enunciado (que é o pensado do juízo), e o argumento (que é o pensado do raciocínio). Â lógica não interessa as operações do pensar, mas sim, o que nelas é pensado como tal. Caso contrário, cai-se no psicologismo, que Husserl tanto combateu em suas Inves- 
demonstrado. Só pode ser manifestado, mostrado, como foi dito anteriormente. E já sempre se mostrou, à medida que se dá a si mesmo por si mesmo diretamente, imediatamente. Como já se indicou, não precisa de rodeios nem de mediações para se chegar a ele. Ele já sempre está aí, como o que há, antes de tudo. Cabe ao intelecto apreendê-lo, numa simples apreensão, numa captação simples do que simplesmente se dá. Sobre o imediatamente evidente não pode haver dúvida. Mas também não pode haver demonstração. É que toda demonstração se faz para aquilo que não é imediatamente evidente. E, no entanto, aquilo que não pode (e não precisa) ser demonstrado é a base para toda demonstração. A noção de ente não pode ser compreendida a partir de qualquer outra noção; entretanto, tudo o que o homem compreende, compreende a partir desta noção.

Portanto, o conhecimento, aqui, tem um sentido transcendental. O que está em jogo, aqui, neste "maxime scibile", diz Heidegger, é o protoelemento (Urelement) do objetual (des Gegenständlich), a saber, a objetualidade (Gegenständlichkeit). O conhecimento do ser é condição de possibilidade do conhecimento de todo e qualquer ente, de todo e qualquer real, de todo e qualquer objeto como tal. O ente é o "maxime scibile" também no sentido de que é o que há de mais certo. Por se dar na auto-evidência da imediatez e de modo originário, por se oferecer sem mediações, desvios, aproximações, gradações, o ente não deixa lugar para dúvida. É um certissimum cognoscibilis (cognoscível certíssimo); o per se inteligibilis (inteligível por si) ${ }^{30}$.

Isso que é sabido originariamente e certissimamente é sabido também como o que há de mais comum. Por ser o originariamente conhecível e inteligível, aquilo sem o que as outras coisas não podem ser sabidas, o ente é algo de "communissimum". Sua originariedade implica sua universalidade. Essa universalidade, porém, não é abstrata, mas concreta. $\mathrm{O}$ ente pode, certamente, ser tomado como um "universal concreto" 31 . O ser emerge em todo sendo, recolhendo na sua unidade todos e cada um dos entes ("seres"). É a identidade comum e indiferenciada que não exclui, antes, promove e inclui todas as diferenças em suas concreções.

No § 1 de Ser e Tempo, Heidegger (2012, p. 3940) procura mostrar que a auto-evidência do ente, que, em linguagem kantiana, pertence aos "juízos secretos da razão comum”, não deve dispensar de um questionamento e de uma investigação. Pelo

tigações Lógicas (Rovighi, 1998, p. 51-52).

30 Quaest. Sup. Met. Prologus, 4b: "Maxime autem dicuntur scibilia dupliciter: vel quia primo omnium sciuntur, sine quibus non possunt alia sciri; vel quia sunt certíssima cognoscibilia. Utroque autem modo ista scientia (scil. Metaphysicia] considerat maxime scibilia... Maxime scibilia primo modo sunt communissima ut est ens inquantum ens et quaecumque sequuntur ens inquantum ens" (Maximamente sabível, porém, se diz de modo duplo: ou porque são sabidos antes de todas as coisas, sem as quais não se podem saber outras coisas; ou porque são conhecíveis certíssimos. De um e de outro modo, porém, esta ciência (a saber, a metafísica) considera os maximamente sabíveis... Maximamente sabíveis no primeiro modo são aquelas coisas que são comuníssimas, como é o ente enquanto ente e o que quer que siga o ente enquanto ente".

31 Toma-se, aqui, emprestada esta expressão de Hegel, sem, todavia a compreender exatamente como ele a entende, segundo a dinâmica dialética de seu pensamento especulativo. contrário. Esta compreensibilidade comum revela um enigma. Nós já sempre vivemos numa compreensão do ser (Seinsverständnis). Esta compreensão é, por assim dizer, o elemento, o medium, em que vivemos e pensamos, e conhecemos o que quer que seja, tudo quanto há. E, no entanto, esta clareza e auto-evidência esconde o sentido de ser, deixa-o envolto na obscuridade. Daí, a necessidade de se colocar a questão do sentido de ser - questão que ficara esquecida na tradição filosófica.

\section{Referências}

Agostinho. (1997). Sobre a potencialidade da alma. Petrópolis: Vozes.

Boaventura de Bagnoreggio. (1999). Escritos Filosófico-Teológicos. Porto Alegre: EDIPUCRS / USF.

Brentano, F. (1996). Sui molteplici significati dell'essere secondo Aristotele. Milano: Vita e Pensiero.

Goris, W. (2015). Transzendentale Einheit. Leiden / Boston: Brill.

Heidegger, M. (1978). Frühe Schriften - Gesammtausgabe Band 1. Frankfurt am Main: Vittorio Klostermann.

Heidegger, M. (1986). Seminare (GA Band 15). Frankfurt am Main: Vittorio Klostermann.

Heidegger, M. (1987). Zur Bestimmung der Philosophie (Gesammtausgabe Band 56/57). Frankfurt am Main: Vittorio Klostermann.

Heidegger, M. (1994). Prolegomena zur Geschichte des Zeitbegriffs (Gesammtausgabe Band 20). Frankfurt am Main: Vittorio Klostermann.

Heidegger, M. (1996). Wegmarken. Frankfurt am Main: Vittorio Klostermann.

Heidegger, M. (2012). Ser e Tempo (7 ${ }^{\mathrm{a}}$ Ed.). Petrópolis / Bragança Paulista: Vozes / EDUSF.

Husserl, E. (1993). Logische Untersuchungen II/2: Elemente einer phänomenologischen Aufklärung der Erkenntnis. Tübingen: Max Niemeyer.

Husserl, E. (2000). Investigações Lógicas: Sexta Investigação (Elementos de uma dilucidação fenomenológica do conhecimento). São Paulo: Nova Cultural.

Iammarrone, L. (2003). Giovanni Duns Scoto Metafisico e Teólogo: le tematiche fondamentali della sua filosofia e teologia. Roma: Miscellanea Francescana.

Kant, I. (1968). Kritik der reinen Vernunft (2. Auflage 1787). Kants Werke III (Akademie Textausgabe). Berlin: Walter De Gruyter.

Rovighi, S. V. (1998). Elementi di filosofia. Vol. I: introduzione, logica, teoria della conoscenza. Milano: La Scuola.

Scot, J. D. (1988). Sur la connaissance de Dieu et l'univocité de l'étant (Introduction, Tradution et commen- 
taire par Olivier Boulnois). Paris: Presses Universitaires de France.

Scotus, I. D. (1950). Opera Omnia II. Civitas Vaticana: Typis Polyglottis Vaticanis.

Scotus, I. D. (1954). Opera Omnia III. Civitas Vaticana: Typis Polygottis Vaticanis.

Scotus, I. D. (1998). Opera Omnia (Editio Minor) I (Opera Philosophica) (a cura di Giovanni Lauriola). Bari: Alberobello.

Marcos Aurélio Fernandes possui graduação em Filosofia pela Universidade São Francisco, Mestrado em Filosofia pelo Pontifício Ateneu Antonianum e Doutorado em Filosofia pela Pontifícia Universidade Antonianum. É Professor Adjunto do Departamento de Filosofia da Universidade de Brasília. Tem experiência na área de Filosofia, com ênfase em Fenomenologia, Filosofia Medieval, Filosofia da Religião e Filosofia da Educação.. Email: framarcosaurelio@hotmail.com

Recebido em 30.03.2018

Aceito em 08.06.2018 